leadership questionnaire of Bass and Avolio and part of the questionnaire on organisational effectiveness was based on multiple constituency approach to organisational effectiveness proposed by Chelladurai. The result of the study indicated that the sports administrators in Nigerian Universities had mainly transactional organisational effectiveness profile. The result further significant correlations between transformational leadership and organisational effectiveness $(r, 688=705<0.05)$ transactional leadership and organisational effectiveness $(r, 688=0.56<0.05)$ and on leadership and organisational effectiveness $(r, 688-0.56<0.05)$. Thus transformational leadership profile explained $0 \%$ transactional leadership profile, $31 \%$ and non-leadership profile, $42 \%$ of the variance in organisational effectiveness. Taken together they showed significant correlations between leadership profiles of sports administrators and sports organisational effectiveness in Nigerian Universities.

\title{
171 RELATION BETWEEN LEADERSHIP PROFILES OF SPORTS ADMINISTRATORS AND SPORTS ORGANISATIONAL EFFECTIVENESS IN NIGERIAN UNIVERSITIES
}

Venkateswarlu Kankanala, ${ }^{1}$ Musa G Yakasail ${ }^{2}$ Department of Physical and Health Education, Ahmadu Bello University, Zaria, Nigeria; ${ }^{2}$ Director of Sports, Bayero University, Kano, Nigeria

\subsection{6/bjsm.2010.078725.171}

Every time the issue of effectiveness in university sports administrations addressed, consideration is given mainly to programme, facilities and funds. There is hardly any mention of quality of leadership of sports administrators, especially in the universities whereas organisational effectiveness appears to depend mainly on the leadership provided. The study was therefore conducted to found out the relationship between leadership profiles of sports administrators and sports organisational effectiveness in Nigerian Universities. To achieve the purpose of the study, a self developed and validated questionnaire on leadership profiles and sports organisational effectiveness was administered to 700 students, representing football, athletics, basketball, racket games and combat sports, randomly selected from 14 Nigerian Universities. Part of the questionnaire on leadership profiles was based on multifactor 